\title{
Политическая активность аудитории постмодерна: коммуникативный аспект
}

\author{
В.C. Тормошева \\ Нижегородский государственный лингвистический университет \\ им. Н.А. Добролюбова, \\ Россия, 603155, г. Нижний Новгород, ул. Минина, 31a \\ E-mail: tormosh@mail.ru
}

\begin{abstract}
Аннотация. На основе коммуникативного подхода опровергнут популярный тезис о политической пассивности аудитории постмодерна. Политическая активность представлена традиционными и нетрадиционными формами в физическом (демонстрации, митинги, марши протеста), сетевом (журналистика гражданская / прямого участия, онлайн-активизм, электронные петиции) и рыночном (политический консьюмеризм, социально ответственное потребление) пространствах. Помимо манифестной деятельности выявлены латентные формы индивидуального и коллективного политического участия (интерес к общественно-политическим вопросам, волонтёрство, политика образа жизни), что значимо для будущих политических действий традиционного формата. Активность может включать легальные конфронтационные практики и незаконные формы (хактивизм, кибертерроризм). Постмодернистская аудитория формирует политическую повестку дня в публичном пространстве, выступая в роли коммуникативного актора.
\end{abstract}

Ключевые слова: аудитория, коммуникация, постмодерн, политическая активность, политическое участие.

Для цитирования: Тормошева В.С. 2020. Политическая активность аудитории постмодерна: коммуникативный аспект. Via in tempore. История. Политология, 47 (3): 647-657. DOI 10.18413/2687-0967-2020-47-3-647-657.

\section{Political activity of the postmodern audience: the communicative aspect}

\author{
Vera S. Tormosheva \\ Nizhny Novgorod State Linguistics University, \\ 31a Minin St., Nizhny Novgorod, 603155, Russia \\ E-mail: tormosh@mail.ru
}

\begin{abstract}
Based on the communicative approach, the article contradicts the common perception about postmodern audience's political passivity. Conventional and unconventional participation formats in three spaces, namely physical (demonstrations, rallies, protests), digital (participatory and network/citizen journalism, online-activism, e-petitioning) and market (political consumerism, socially conscious consumption) represent its political activity. In addition to its manifest activities, the postmodern audience practises latent forms of individual and collective political participation (interest in politics and societal issues, voluntary work, lifestyle related politics) that could be of great relevance for future political actions of a more traditional dimension. Political activity may include legal confrontational practices as well as illegal forms of political participation (hacktivism, cyberterrorism). As a communicative actor, the postmodern audience has been defining the political agenda in the public sphere.
\end{abstract}

Keywords: audience, communication, postmodernity, political activity, political participation. 
For citation: Tormosheva V.S. Political Activity of the Postmodern Audience: The Communicative Aspect. Via in tempore. History and political science, 47 (3): 647-657 (in Russian). DOI 10.18413/2687-0967-2020-47-3-647-657.

\section{Введение}

Исследование коммуникации в политической сфере вызывает пристальное внимание учёных, политиков, управленцев и специалистов-практиков начиная с 1940-х годов. В условиях постмодернистских трансформаций, коснувшихся в числе прочего политической коммуникации, возникает необходимость изучения коммуникативной составляющей многочисленных аспектов политического процесса. Одним из таких аспектов представляется политическая активность аудитории постмодерна, пока ещё не получившая рассмотрения с использованием коммуникативного подхода.

Аудиторию постмодерна, именуемую «искусственным образованием» либо «воображаемым сообществом», нелегко определить. Исследователи-постмодернисты разделяют мнение о её сложности и отмечают проблематичность установления с ней политического контакта, падение избирательной лояльности, отсутствие у неё «подчинённого положения» по отношению к СМИ, дефицит интереса к важным политическим новостям, их избегание, нацеленность на развлечения и изменчивость политических предпочтений [Тормошева, 2018, с. 474, 476]. Кроме того, достаточно распространено мнение о социальнополитической пассивности постмодернистской аудитории. Свидетельство этому - множество ярких, негативно окрашенных метафор в её адрес, а именно: «бесформенное население» на театрализованном представлении [Шепелев, 2019, с. 92]; «люди, ранее известные как аудитория», живущие внутри сформированного их предпочтениями и интернеталгоритмами «информационного пузыря» [Bennett, Pfetsch, 2018, pp. 245, 248]; «наблюдатели», застывшие в ожидании императива для выполнения политического действия [Ekman, Amnå, 2012, p. 288]; некомпетентные, ситуативно реагирующие, контрпродуктивные «акторы» [Семёнов, 2019, с. 176], а также пришедшие на смену телеаудитории «диванных активистов» политически неэффективные, лишённые моральных устоев «кликактивисты», имеющие конечной целью удовлетворение личных, а не общественных устремлений [Cabrera et al., 2017, pp. 5, 7].

Исследования, однако, показывают, что так называемые неучаствующие в политике составляют в обществе меньшинство. Опрос британских граждан об их отношении к политической деятельности свидетельствует, что $60 \%$ так или иначе вовлечены в политическую жизнь. Это исполнители (37 \%), не имеющие склонности к партийной работе, но достаточно активные на уровне местных сообществ; эксперты $(15 \%)$, использующие знания и связи с целью влияния на политические и корпоративные элиты по определённому кругу проблем и политические активисть $(8 \%)$, действующие в рамках традиционной политической деятельности и имеющие схожие с экспертами характеристики [Slade, Hobbs, 2015, p. 2]. Результаты выявления актуального и перспективного интереса россиян к политике показывают, что более 75 \% опрошенных имеют систематический либо периодический запрос на политическую информацию; отсутствует интерес к политическим событиям у менее 18 \% респондентов [Гаврилюк, Маленков, 2019, с. 46].

Более того, изучение электорального поведения молодёжи США, Великобритании, Франции, Германии и России опровергает как расхожее представление об утрате молодым поколением интереса к политике, так и широко распространённый в западном и российском научном сообществе тезис о размывании традиционных форм политического участия в связи со сменой поколений и изменением условий социализации [Пырма, 2019, с. 188]. Концепции отмирания демократических институтов ввиду падения интереса граж- 
дан к политике и замещения политически активных поколений пассивными также не находят подтверждения [Там же, с. 197].

В качестве гипотезы нашего исследования мы выдвигаем следующее утверждение: современные коммуникативные практики влияют на политическую активность аудитории, стимулируя её. Основанием для нашего утверждения служит то, что для постмодерна характерна повышенная концентрация информационных потоков (графических, символьных, текстовых, аудио, видео и их комбинаций), что воздействует на гражданина через множество коммуникационных каналов (межличностных, наружно-рекламных, событийных, печатных, вещательных, сетевых). Согласно исследованиям, чем выше количество информационных каналов в репертуаре отдельного пользователя, тем больше времени он посвящает именно новостным программам [Wonneberger, Kim, 2017, p. 85], что, несомненно, повышает его информированность в общественно-политической проблематике и формирует критическое отношение к политической системе в целом и/или к её элементам. В конечном счёте это выражается в высказываниях либо в действиях политического характера в публичном пространстве.

\section{Методология исследования}

Использование коммуникативного подхода в политической мысли отражено в многочисленных работах, ставших классикой социально-политических наук. Здесь следует назвать труды Толкотта Парсонса, Карла Дойча, Ханны Арендт, Никласа Лумана, Георгия Почепцова и др. Наиболее важной для нашего исследования является теория коммуникативного действия немецкого социолога, философа и теоретика постмодернизма Юргена Хабермаса и его утверждение об интерактивном участии индивидов в коммуникативных действиях в онлайн- и офлайн-среде как условии построения глобального политического пространства.

В статье мы предпримем попытку систематизировать разновидности политической активности аудитории постмодерна, обусловленные коммуникативными действиями в онлайн- и офлайн-среде. Вслед за теоретиком постмодернизма Фредриком Джеймсоном подчеркнём, что разнообразные современные политические практики не являются политическими событиями в традиционном понимании: они недолговечны и не имеют значительных институциональных последствий. Это «события» в философском смысле слова: они существуют в настоящем, а затем заканчиваются, отражая главную черту постмодерна - презентизм коммуникаций [Baumbach et al., 2016, p. 146].

Помимо коммуникативного подхода мы используем данные теоретических и эмпирических исследований политической активности граждан отдельных европейских стран (России, Бельгии, Великобритании, Германии, Нидерландов, Франции, Швейцарии, Швеции), Европейского Союза в целом и США, что позволит определить актуальные тренды политического участия в современном мировом политическом процессе.

\section{Традиционные и новые политические практики аудитории постмодерна}

Не разделяя мнение о политической пассивности постмодернистской аудитории, некоторые учёные отмечают её значительную роль с точки зрения политиков и СМИ. Именно поэтому политические и медийные акторы постоянно учитывают интересы и требования граждан при формулировании и адресации политических сообщений [Esser, Pfetsch, 2017, p. 6]. Публикуя, комментируя и интерпретируя результаты опросов общественного мнения, СМИ, в свою очередь, помещают политиков под пресс общественного мнения. В результате взаимного влияния друг на друга политических акторов, медиа и аудитории, предъявляющих информацию в виде требований, призывов, обращений, соображений и аргументов, в ведущих, нишевых, цифровых и социальных медиа происходит формирование множества политических повесток [Bennett, Pfetsch, 2018, p. 249]. 
Отметим по крайней мере два момента, связанные с политической ролью традиционной практики проведения опросов общественного мнения. Bo-nервых, опросы снижают стоимость индивидуального выражения политических взглядов. Участие в демонстрации требует временны́х и энергетических затрат, подписание петиций может быть связано с риском, в то время как анонимное участие в опросе минимально по затратам, что позволяет вовлечь даже равнодушных и незаинтересованных в политике граждан. Bo-вторых, мирный характер опросов облегчает выражение политических взглядов, в то время как участие в демонстрациях связано с угрозой насилия, особенно когда мнения участников достаточно полярны.

Помимо деления граждан на занятых политикой либо равнодушных к ней, важно отметить новое понимание гражданами политики, обусловленное утратой доверия к традиционным политическим институтам, с одной стороны, и появлением новых коммуникационных возможностей самовыражения, с другой [Парфёнова, 2016, с. 12]. На смену традиционному формату политического участия с официально установленными видами общественно-политической деятельности [Lamprianou, 2013, p. 22] приходят неконвенциональные политические практики [Slade, Hobbs, 2015, p. 2]. При этом исследовательский интерес по-прежнему сфокусирован на традиционных формах политического участия.

Подобная ситуация приводит к тому, что инновации в политическом репертуаре граждан остаются незамеченными, и, как следствие, формируются ложные представления об аполитичности аудитории постмодерна [Stolle et al., 2005, p. 249]. Напротив, дистанцирование от традиционной политики и её структур, а также всплеск неинституциональных форм политического участия [Cabrera et al., 2017, pp. 3-5] - неотъемлемая часть бурных постмодернистских трансформаций политического пространства [Lamprianou, 2013, p. 28]. Граждане бросают вызов элитам, участвуя в мирных шествиях, демонстрациях и митингах. Активные бойкоты и протесты могут сопровождаться строительством баррикад, поджогами, нападением на силы безопасности, порчей имущества, нанесением граффити. Политическими площадками являются и виртуальные ресурсы - блогосфера, видеохостинги и социальные сети. При всём многообразии постмодернистских форм политического участия они могут быть как незаконными, так и правомерными, но при этом агрессивными либо экстремальными [Lamprianou, 2013, p. 25].

Отметим ещё одну важную тенденцию, заметную в научной литературе. Исследовательский фокус обнаруживается на манифестной политической практике, т. е. партийной, протестной, контактной или электоральной деятельности. Латентные, или неявные индивидуальные и коллективные формы, среди которых волонтёрство, интерес к общественно-политическим вопросам, политика принадлежности к определённому образу жизни, фактически игнорируются учёными [Ekman, Amnå, 2012, pp. 284, 287, 292]. В то же время латентные формы политического участия при всей сложности и неоднозначности их систематизации и классификации тем не менее значимы для политических действий в будущем.

\section{Политическая активность вне физического пространства}

Информационно-коммуникационные технологии (далее ИКТ) позволяют постмодернистской аудитории преодолевать границы физического пространства. Аудитория становится просьюмером (от англ. prosumer), или «производящим потребителем» новостного контента, т. е. его создателем и распространителем [Wonneberger, Kim, 2017, p. 86]. Многочисленные социальные интернет-платформы позволили обсуждению политических событий эволюционировать в политическое онлайн-участие: «один на один» (твиты с открытым доступом), «один ко многим» (перепосты сообщений пользователей) и «многих со многими» (распространение информации с использованием хэштэгов). Другими словами, нарастает коммуникативная активность аудитории, включающая в себя отбор, воспроизводство, редактирование, изменение, комментирование, создание и мгновенное ти- 
ражирование печатного, фото-, аудио- или видеоконтента с использованием практически неограниченных «кроссплатформенных коммуникативных практик» на стыке интернетресурсов, спутниковых каналов, мобильных приложений, стримингового телевидения и традиционных медиа форм [Volkmer, 2019, p. 253]. Сети не просто объединяют «друзей» по принципу относительной схожести в общении, развлечении и познавательной деятельности [Зайко, 2017, с. 110], а выполняют роль виртуальных публичных пространств, для которых не существует ни локальных, ни национальных границ. Более того, виртуальная мобильность пользователя, находящегося в естественном социокультурном пространстве и обеспеченная многочисленными и доступными ИКТ, позволяет ему стать международным актором, создающим, развивающим и/или поддерживающим транснациональные связи [Тормошева, 2015, с. 188].

Онлайн-активизм касается растущего использования социальных сетей как механизма влияния на принятие политических решений по общественно-значимым проблемам обеими категориями аудиторий - оппозиционными и лояльными власти [Гончаров, Нечай, 2018 , с. 65]. Он связан с проведением политических кампаний как в онлайн-среде, так и стимулирует политическую активность в физическом пространстве. К примеру, британское политическое движение «38 Degrees», объединяющее два с половиной миллиона участников, проводит интернет-кампании демократической, социальной и экологической направленности. Российское движение А. Навального в защиту прав граждан и против коррупции является ярким примером того, как онлайн-активность по информированию, координированию и мобилизации сторонников приводит к масштабным офлайн-акциям [Соколов, Курбанова, 2019, с. 242-243]. В научной среде пока отсутствует единодушное отнесение онлайн-комментирования, репоста политического контента, подписания электронной петиции или иного вида онлайн-активизма к политическому участию. При этом онлайн-комментирование политического контента обоснованно рассматривается как один из способов политической мобилизации в контексте цифрового политического участия [Радина, 2018, с. 115].

Ряд экстремальных форм политического онлайн-активизма, требующих высокого уровня технической компетентности, может быть отнесён к незаконным. Здесь следует отметить компьютерное хакерство (хактивизм), т. е. социально мотивированное проникновение в компьютерную систему. Хактивисты-одиночки или члены международных хактивистских движений (Anonymous, Chaos Computer Club, Red Hacker Alliance, Unity и др.) повреждают сайты, похищают информацию, организуют атаки на серверы. Подобные действия, как правило, не основаны на целостной идеологии, а точечно направлены против авторитарных режимов, капиталистических ценностей или цензурных ограничений [Slade, Hobbs, 2015, p. 3]. Деятельность хактивистов часто характеризуют как кибертерроризм. Так называемый «кибертеррорист с ноутбуком» осуществляет несанкционированное проникновение на официальные интернет-ресурсы органов государственной власти, ведущих СМИ, крупнейших бизнес-структур, операторов спутниковой связи и других стратегически важных организаций, а затем разглашает конфиденциальную информацию, публикует фейковые посты в соцсетях либо вмешивается в информационную повестку самих ресурсов [Акопов, 2015, с. 196-197].

Доступность интернета в сочетании с интерактивным характером ИКТ порождают новые формы «журналистской» активности - журналистику прямого участия (participatory journalism) и гражданскую/сетевую журналистику (citizen/network journalism) [Bakker, Paterson, 2011, pp. 187-190]. Новые форматы позволяют постмодернистской аудитории публично обсуждать общественно-политические вопросы, формируя политическую повестку, что ранее было исключительно прерогативой политиков и журналистов. В случае с журналистикой прямого участия фото-, видео-, аудиоматериалы и комментарии пользователей с мест событий вписываются в уже существующую новостную практику той или иной медийной структуры. Представители СМИ модерируют полученные ма- 
териалы, приводят их в соответствие журналистским нормам и редакционной политике издания. Гражданская/сетевая журналистика, напротив, характеризуется практически полным отсутствием редакторского контроля пользовательских публикаций. Аудитория сама определяет место размещения созданного контента: бесплатные интернетплатформы для распространения видеоматериалов; ресурсы с допуском к редактированию материалов пользователей; интерактивные сети для мгновенного публичного обмена сообщениями. Отметим её способность генерировать информационные лавины - «скоротечные и мощные всплески создания, размножения и передачи информации» вне зависимости от значимости информационного повода [Жуков,_2018, с. 18], что, несомненно, ускоряет формирование политической повестки и усложняет её тематическое наполнение. Гражданская журналистика отражает множество умонастроений, включая распространение дискриминационных, расистских, ксенофобских, националистических и т. п. взглядов. Она способствует объективности либо предвзятости в освещении событий и может оказывать влиятельную поддержку тех или иных политических идей.

\section{Политическая активность в пространстве рынка}

Нельзя не отметить тенденцию появления нового места приложения политических действий, а именно рынка. Основные маркетинговые технологии (политический PR, политическая имиджистика, играизация, шоуизация, эстетизация и «гламуризация» политики), используемые политиками и СМИ, являются средствами продвижения на политическом рынке политической продукции - идей, платформ, партийных программ, решений и т. п. Их использование основано на убеждении в эффективности рыночных методов влияния на политические субъекты и скепсисе относительно традиционных форм политического участия [Кудлай, 2016, с. 97]. С другой стороны, граждане используют рынок для выражения политических взглядов. Не только политические институты и системы подвергаются воздействию, но и рыночные акторы. Акт выражения политического предпочтения носит название политический консьюмеризм [Zorell, 2019, p. 16].

Термин «политический консьюмеризм» активно входит в обиход политической науки в эпоху постмодерна и подразумевает два взаимосвязанных и взаимообусловленных явления: (1) потребительское поведение, мотивированное политически (так называемое позитивное потребление (buycott) товаров и услуг, отвечающих ценностям устойчивого развития, социальной справедливости и корпоративной ответственности, либо бойкот (boycott) товаров и услуг, не отвечающих этим ценностям) [Rössel, Schenk, 2018, p. 267]; (2) политическое поведение, мотивированное потребительски (отношение граждан к политике как к рыночной сфере, где продвигаются и покупаются политические «товары» программы, кандидаты, партии и т. п.). Замечено, что в политическом поведении россиян доминирует консьюмеризм во втором значении этого слова. И, напротив, потребительское поведение, мотивированное политически, представлено достаточно слабо. Согласно опросам, 60 \% населения Швеции и Швейцарии практикуют позитивное потребление, а 40 \% американцев - бойкоты брендов и товаров по политическим мотивам [Ibid, p. 267].

Политический консьюмеризм, одним из проявлений которого называют социально ответственное потребление, относят к новым формам политического участия, которые приходят на смену или дополняют традиционные практики политического участия и мотивируются этическими проблемами, экологической обстановкой и/или политической ситуацией. Размышления над ролью социально ответственного потребления в изменении природы демократической гражданственности показывают, что этический выбор (уважение к окружающей среде, неиспользование детского труда, поддержка малых производств и т. п.) выступает для потребителя привлекательной формой выражения политических предпочтений, что расширяет глубину и содержание понятия «политическое» и включает гражданскую составляющую в повседневную жизнь [García Espejo, Novo Vázquez, 2017, p. 73]. 
Исследования подтверждают тесную взаимосвязь медиа и политического консьюмеризма. Так, более 80 \% граждан получают информацию о кампаниях поддержки или бойкота товаров через каналы массовой коммуникации [Ibid, p. 64]. Однако политический консьюмеризм представлен не только в виде журналистского «продукта» в медиасфере. Современная реальность предполагает использование не только традиционных печатных и вещательных, но и альтернативных цифровых каналов коммуникации, где не профессиональные журналисты, а сами политические потребители выступают авторами контента, так называемыми «produsers» (от англ. «produsage», ещё не закреплённого в словарях) [Boström et al., 2019, p. 8]. Интернет-платформы являются как местом размещения общественно-значимой информации, так и пространством политического участия в виде «дискурсивных действий», где выражаются мнения, приводятся факты, даются оценки и выдвигаются требования к корпоративной политике компаний и качеству их продукции [Zorell, 2019, p. 42].

Заслуживает внимания положительная динамика политического консьюмеризма. К примеру, социально ответственное потребление на регулярной основе выросло в Германии с 26 \% в 2009 г. до 56 \% в 2013 г. Великобритания за период с 2000 по 2012 гг. показала рост с $27 \%$ до 42 \% [Ibid, p. 2]. С 1970-х гг. потребительское бойкотирование в Европе в пять раз превысило рост таких форм политической активности, как подписывание петиций, участие в демонстрациях и захват зданий [Rössel, Schenk, 2018, p. 268]. Потребительское бойкотирование опережает участие в работе политических партий и др. объединений гражданского общества и взаимодействие с политическими, медийными акторами и госслужащими [Stolle et al., 2005, pp. 247-248].

Примеры политического консьюмеризма показывают, что граждане используют политические цели и ценности, имея мишенью компании, международные организации или привлекая общественное внимание. Подобные действия направлены не только на достижение правовых изменений на национальном уровне, но и на регулирование международного рынка труда, что не входит в компетенции национальных правительств. Делая индивидуальный или коллективный выбор, граждане руководствуются соображениями честности, справедливости или собственной оценкой деятельности бизнес-структур или правительств [Ibid, p. 246].

Опросы студентов-социологов Бельгии, Канады и Швеции показывают, что политический консьюмеризм является неотъемлемой частью политической деятельности молодёжи в целом. Кроме того, молодые политические потребители достаточно активны в других формах политического участия. Справедливо и то, что они разочарованы действиями господствующих политических институтов и недостаточно высоко оценивают традиционные формы политического участия [Ibid, pp. 262-264].

Добавим, что исследование использования гражданами рынка как политической арены с неинституциональными формами политического участия позволяет расширить концепт политики и признать роль рынка и рыночных акторов в политической мобилизации. Новое место применения политических действий поднимает вопрос о новом содержании понятий «политическая активность», «политическое участие», «политический потребитель» и «гражданин постмодерна» [García Espejo, Novo Vázquez, 2017, p. 62].

\section{Заключение}

Итак, для постмодернистской аудитории характерно множество «коммуникативных действий» (по Хабермасу), или форм политического участия, включая традиционные, соответствующие закреплённым политическим нормам (например, выражение политических взглядов через опросы общественного мнения, голосование, членство в политической партии), и нетрадиционные, представленные многочисленными классификациями. Политическая активность постмодернистской аудитории проявляется в физическом пространстве (демонстрации, митинги, марши протеста), онлайн-пространстве (журналистика 
прямого участия, гражданская/сетевая журналистика, онлайн-активизм, подписание электронных петиций) и рыночном пространстве (политический консьюмеризм, включая социально ответственное потребление). Помимо манифестной деятельности аудитории используют латентные формы индивидуального и коллективного политического участия (интерес к общественно-политическим вопросам, волонтёрство, принадлежность к определённому образу жизни и др.), что значимо для будущих политических действий более традиционного формата. Кроме того, активность может включать легальные конфронтационные виды политического участия и незаконные, опирающиеся на хакерство, практики хактивизма и кибертерроризма. Постмодернистская аудитория наряду с политиками и журналистами занимает место в ряду коммуникативных акторов, формирующих в публичном пространстве политическую повестку и оказывающих коммуникативное влияние своими призывами, обращениями, требованиями и комментариями посредством интернетплатформ.

\section{Список литературы}

1. Акопов Г.Л. 2015. Хактивизм - угроза информационной безопасности в информационном социуме. Государственное и муниципальное управление. Учёные записки СКАГС, 3: 195-199.

2. Гаврилюк В.В., Маленков В.В. 2019. Новое поколение граждан и телевидение. Известия УрФУ. Сер. 3. Общественные науки, 14, 1(185): 42-53.

3. Гончаров Д.В., Нечай В.В. 2018. Антикоррупционные протесты 2017: Отражение в Твиттере. Полития, 1(88): 65-81. DOI: 10.30570/2078-5089-2018-88-1-65-81.

4. Жуков Д.С. 2018. Прерывистый эквилибриум: как самоорганизованная критичность в Сети влияет на политическую повестку дня. Журнал политических исследований, 2(4): 18-40.

5. Зайко А.П. 2017. Социальная активность студентов колледжей в социальных сетях: региональный аспект. Известия УрФУ. Сер. 3. Общественные науки, 12, 2 (164): 106-113.

6. Кудлай А.А. 2016. Политическая власть и политический рынок: новые формы участия. Исторические, философские, политические и юридические науки, культурология и искусствоведение. Вопросы теории и практики. Тамбов: Грамота, 4 (66): 96-98.

7. Парфёнова Ю.В. 2016. Сетевые формы политического участия в современной России и постсоветском пространстве. Автореф. дис. ... канд. полит. наук. СПб., 20.

8. Пырма Р.В. 2019. Электоральная активность молодёжи в США, Великобритании, Франции, Германии и России. Сравнительное исследование. Полития, 4 (95): 188-204. DOI: 10.30570/2078-5089-2019-95-4-188-204.

9. Радина Н.К. 2018. Цифровая политическая мобилизация онлайн-комментаторов материалов СМИ о политике и международных отношениях. Полис. Политические исследования, 2: 115-129. DOI: 10.17976/jpps/2018.02.09.

10. Семёнов В.С. 2019. Кризис глобального управления в современном мире: риски, угрозы безопасности, перспективы. В кн.: Альбеков А.У., Старостин А.М. (ред.) Междисциплинарные проблемы международных отношений в глобальном контексте. Ростов н/Д., изд.-полигр. комплекс РГЭУ (РИНХ): 173-176.

11. Соколов А.В., Курбанова А.А. 2019. Массовые движения в современной России (на примере движения в поддержку А. Навального). Вестник Томского государственного университета. Cер. Философия. Социология. Политология, 52: 231-245. DOI: 10.17223/1998863X/52/21.

12. Тормошева В.С. 2018. «Невнимательная» аудитория как проблема международнополитической коммуникации постмодерна. В кн.: Четвёртая промышленная революция: реалии и современные вызовы. Материалы международной научной конференции (Санкт-Петербург, 13-14 апреля 2018 г.). СПб., Изд-во Политехн. ун-та: 474-477.

13. Тормошева В.С. 2015. Постмодернистский индивид: «бессильный субъект» или влиятельный актор международной политики? Известия высших учебных заведений. Сер. Гуманитарные науки, 6 (3): 186-190.

14. Шепелев М.А. 2019. Цивилизация Ультрамодерна и её кризис. В кн.: Альбеков А.У., Старостин А.М. (ред.) Междисциплинарные проблемы международных отношений в глобальном контексте. Ростов н/Д., изд-полигр. комплекс РГЭУ (РИНХ): 89-94. 
15. Bakker T., Paterson C. 2011. The New Frontiers of Journalism: Citizen Participation in the United Kingdom and the Netherlands. In: Brants K., Voltmer K. (eds.) Political Communication in Postmodern Democracy: Challenging the Primacy of Politics. Basingstoke: 183-199.

16. Baumbach N., Young D.R., Yue G. 2016. Revisiting Postmodernism: An Interview with Fredric Jameson. Social Text, 34 (2 (127)): 143-160. DOI: 10.1215/01642472-3468026.

17. Bennett W.L., Pfetsch B. 2018. Rethinking Political Communication in a Time of Disrupted Public Spheres. Journal of Communication, 68: 243-253. DOI: 10.1093/joc/jqx017.

18. Boström M., Micheletti M., Oosterveer P. 2019. Studying Political Consumerism. In: Boström M., Micheletti M., Oosterveer P. (eds.) The Oxford Handbook of Political Consumerism. N.Y., Oxford University Press: 1-24.

19. Cabrera N.L., Matias C.E., Montoya R. 2017. Activism or Slacktivism? The Potential and Pitfalls of Social Media in Contemporary Student Activism. Journal of Diversity in Higher Education, 10 (4): 400-415. DOI: $10.1037 /$ dhe0000061.

20. Ekman J., Amnå E. 2012. Political Participation and Civic Engagement: Towards a New Typology. Human Affairs, 22: 283-300. DOI: 10.2478/s13374-012-0024-1.

21. Esser F., Pfetsch B. 2017. Comparing Political Communication. In: Caramani D. (ed.) Comparative Politics. N.Y., Oxford University Press: 327-345.

22. García Espejo I., Novo Vázquez A. 2017. The Emergence of the 'Conscious Consumer': An Analysis of Political Participation through Purchasing Decisions. Rev. Esp. Investig. Sociol., 158: 59-78. DOI: $10.5477 /$ cis/reis.158.59.

23. Lamprianou I. 2013. Contemporary Political Participation Research: A Critical Assessment. In: Demetriou K. (ed.) Democracy in Transition. Political Participation in the European Union. Berlin, Springer Verlag: $21-42$.

24. Rössel J., Schenk P.H. 2018. How Political is Political Consumption? The Case of Activism for the Global South and Fair Trade. Social Problems, 65: 266-284. DOI: 10.1093/socpro/spx022.

25. Slade D., Hobbs A. 2015. Trends in Political Participation. POSTnote, 498, 7.

26. Stolle D., Hooghe M., Micheletti M. 2005. Politics in the Supermarket: Political Consumerism as a Form of Political Participation. International Political Science Review, 26: 245-269. DOI: $10.1177 / 0192512105053784$.

27. Volkmer I. 2019. The Transnationalization of Public Spheres and Global Policy. In: Stone D., Moloney K. (eds.) The Oxford Handbook of Global Policy and Transnational Administration. N.Y., Oxford University Press: 240-256.

28. Wonneberger A., Kim S.J. 2017. TV News Exposure of Young People in Changing Viewing Environments: A Longitudinal, Cross-national Comparison Using People-meter Data. International Journal of Communication, 11: 72-93.

29. Zorell C. 2019. Varieties of Political Consumerism: From Boycotting to Buycotting. Cham, Palgrave Macmillan, 188.

\section{References}

1. Akopov G.L. 2015. Haktivizm - ugroza informacionnoj bezopasnosti v informacionnom sociume [Cyber troops as the basis of information security]. State and Municipal Management. Scholar Notes, 3: 195-199 (in Russian).

2. Gavrilyuk V.V., Malenkov V.V. 2019. Novoe pokolenie grazhdan i televidenie [The new generation of citizens and television]. Izvestia. Ural Federal University Journal. Series 3. Social and Political Sciences, 14, 1 (185): 42-53 (in Russian).

3. Goncharov D.V., Nechaj V.V. 2018. Antikorrupcionnye protesty 2017: Otrazhenie v Tvittere [Anti-corruption protests 2017: reflection in Twitter]. Politeia, 1 (88): 65-81 (in Russian). DOI: 10.30570/2078-5089-2018-88-1-65-81.

4. Zhukov D.S. 2018. Preryvistyj jekvilibrium: kak samoorganizovannaja kritichnost' v Seti vlijaet na politicheskuju povestku dnja [Punctuated equilibrium: how network self-organized criticality affects the political agenda]. Journal of Political Research, 2 (4): 18-40 (in Russian).

5. Zayko A.P. 2017. Social'naja aktivnost' studentov kolledzhej v social'nyh setjah: regional'nyj aspekt [College students' social activity in social network: regional aspect]. Izvestia. Ural Federal University Journal. Series 3. Social and Political Sciences, 12, 2 (164): 106-113 (in Russian). 
6. Kudlai A.A. 2016. Politicheskaja vlast' i politicheskij rynok: novye formy uchastija [Political power and political market: new forms of participation]. Historical, Philosophical, Political and Law Sciences, Culturology and Study of Art. Issues of Theory and Practice. Tambov, Gramota, 4 (66): 96-98 (in Russian).

7. Parfyonova Ju.V. 2016. Setevye formy politicheskogo uchastija v sovremennoj Rossii i postsovetskom prostranstve [Network forms of political participation in contemporary Russia and in the post-Soviet area]. Abstract. dis. ... cand. polit. sciences. SPb, 20 (in Russian).

8. Pyrma R.V. 2019. Jelektoral'naja aktivnost' molodjozhi v SShA, Velikobritanii, Francii, Germanii i Rossii. Sravnitel'noe issledovanie [Electoral participation of youth in the USA, Great Britain, France, Germany, and Russia. Comparative study]. Politeia, 4 (95): 188-204 (in Russian). DOI: 10.30570/2078-5089-2019-95-4-188-204.

9. Radina N.K. 2018. Cifrovaja politicheskaja mobilizacija onlajn-kommentatorov materialov SMI o politike i mezhdunarodnyh otnoshenijah [Digital Political Mobilization of Online Commenters on Publications about Politics and International Relations]. Polis. Political Studies, 2: 115-129 (in Russian). DOI: $10.17976 /$ jpps/2018.02.09.

10. Semyonov V.S. 2019. Krizis global'nogo upravlenija v sovremennom mire: riski, ugrozy bezopasnosti, perspektivy [The crisis of global management in the modern world: risks, security threats, perspectives]. V kn.: Al'bekov A.U., Starostin A.M. (eds.) Mezhdisciplinarnye problemy mezhdunarodnyh otnoshenij $\mathrm{v}$ global'nom kontekste [Interdisciplinary problems of international relations in a global context]. Rostov-on-Don, izd.-poligr. kompleks RGJeU (RINH): 173-176 (in Russian).

11. Sokolov A.V., Kurbanova A.A. 2019. Massovye dvizhenija v sovremennoj Rossii (na primere dvizhenija v podderzhku A. Naval'nogo) [Mass movements in modern Russia (on the example of the movement in support of A. Navalny)]. Tomsk State University Journal of Philosophy, Sociology and Political Science, 52: 231-245 (in Russian). DOI: 10.17223/1998863X/52/21.

12. Tormosheva V.S. 2018. «Nevnimatel'naja» auditorija kak problema mezhdunarodnopoliticheskoj kommunikacii postmoderna [«Inattentive» public as a problem of postmodern internationalpolitical communication]. V kn.: Chetvjortaja promyshlennaja revoljucija: realii i sovremennye vyzovy. Materialy mezhdunarodnoy nauchnoy konferentsii [The fourth industrial revolution: the realities and challenges of today. Materials of international scientific conference] (Saint Petersburg, 13-14 April 2018). SPb, Saint Petersburg State Polytechnic University Publ. House: 474-477 (in Russian).

13. Tormosheva V.S. 2015. Postmodernistskij individ: «bessil'nyj sub"ekt» ili vlijatel'nyj aktor mezhdunarodnoj politiki? [The postmodern individual: a powerless subject or a powerful actor of international politics?]. News of Higher Schools. Series «Humanities», 6 (3): 186-190 (in Russian).

14. Shepelev M.A. 2019. Civilizacija Ul'tramoderna i ejo krizis [Civilization of Ultramodern and its crisis]. V kn.: Al'bekov A.U., Starostin A.M. (eds.) Mezhdisciplinarnye problemy mezhdunarodnyh otnoshenij v global'nom kontekste [Interdisciplinary problems of international relations in a global context]. Rostov-on-Don, izd-poligr. kompleks RGJeU (RINH): 89-94 (in Russian).

15. Bakker T., Paterson C. 2011. The New Frontiers of Journalism: Citizen Participation in the United Kingdom and the Netherlands. In: Brants K., Voltmer K. (eds.) Political Communication in Postmodern Democracy: Challenging the Primacy of Politics. Basingstoke: 183-199.

16. Baumbach N., Young D.R., Yue G. 2016. Revisiting Postmodernism: An Interview with Fredric Jameson. Social Text, 34 (2 (127)): 143-160. DOI: 10.1215/01642472-3468026.

17. Bennett W.L., Pfetsch B. 2018. Rethinking Political Communication in a Time of Disrupted Public Spheres. Journal of Communication, 68: 243-253. DOI: 10.1093/joc/jqx017.

18. Boström M., Micheletti M., Oosterveer P. 2019. Studying Political Consumerism. In: Boström M., Micheletti M., Oosterveer P. (eds.) The Oxford Handbook of Political Consumerism. N.Y., Oxford University Press: 1-24.

19. Cabrera N.L., Matias C.E., Montoya R. 2017. Activism or Slacktivism? The Potential and Pitfalls of Social Media in Contemporary Student Activism. Journal of Diversity in Higher Education, 10 (4): 400-415. DOI: $10.1037 /$ dhe0000061.

20. Ekman J., Amnå E. 2012. Political Participation and Civic Engagement: Towards a New Typology. Human Affairs, 22: 283-300. DOI: 10.2478/s13374-012-0024-1.

21. Esser F., Pfetsch B. 2017. Comparing Political Communication. In: Caramani D. (ed.) Comparative Politics. N.Y., Oxford University Press: 327-345. 
22. García Espejo I., Novo Vázquez A. 2017. The Emergence of the 'Conscious Consumer': An Analysis of Political Participation through Purchasing Decisions. Rev. Esp. Investig. Sociol., 158: 59-78. DOI: $10.5477 /$ cis/reis.158.59.

23. Lamprianou I. 2013. Contemporary Political Participation Research: A Critical Assessment. In: Demetriou K. (ed.) Democracy in Transition. Political Participation in the European Union. Berlin, Springer Verlag: 21-42.

24. Rössel J., Schenk P.H. 2018. How Political is Political Consumption? The Case of Activism for the Global South and Fair Trade. Social Problems, 65: 266-284. DOI: 10.1093/socpro/spx022.

25. Slade D., Hobbs A. 2015. Trends in Political Participation. POSTnote, 498, 7.

26. Stolle D., Hooghe M., Micheletti M. 2005. Politics in the Supermarket: Political Consumerism as a Form of Political Participation. International Political Science Review, 26: 245-269. DOI: $10.1177 / 0192512105053784$.

27. Volkmer I. 2019. The Transnationalization of Public Spheres and Global Policy. In: Stone D., Moloney K. (eds.) The Oxford Handbook of Global Policy and Transnational Administration. N.Y., Oxford University Press: 240-256.

28. Wonneberger A., Kim S.J. 2017. TV News Exposure of Young People in Changing Viewing Environments: A Longitudinal, Cross-national Comparison Using People-meter Data. International Journal of Communication, 11: 72-93.

29. Zorell C. 2019. Varieties of Political Consumerism: From Boycotting to Buycotting. Cham, Palgrave Macmillan, 188.

\section{ИНФОРМАЦИЯ ОБ АВТОРЕ}

Тормошева Вера Сергеевна, соискатель кафедры международных отношений и политологии Нижегородского государственного лингвистического университета им. Н.А. Добролюбова, г. Нижний Новгород, Россия

\section{INFORMATION ABOUT THE AUTHOR}

Vera S. Tormosheva, postgraduate degree seeker of the International Relations and Political Science Department, Nizhny Novgorod State Linguistics University, Nizhny Novgorod, Russia 